\title{
ROBUST SECOND ORDER SLIDING MODE CONTROL OF DOUBLY-FED INDUCTION GENERATOR FOR WIND ENERGY CONVERSION SYSTEM
}

\author{
Youcef DJERIRI \\ Department of Electrical Engineering, Faculty of Electrical Engineering \\ Djillali Liabes University, Intelligent Control and Electrical Power Systems Laboratory, PO Box 89, Sidi Bel-Abbes, 22000, Algeria \\ E-mail: youcef.djeriri@univ-sba.dz
}

\begin{abstract}
This paper presents a robust nonlinear control strategy based on second-order continuous sliding mode control called SuperTwisting Sliding Mode Control (ST-SMC) strategy of a doubly-fed induction generator (DFIG) integrated into a Wind Energy Conversion System (WECS). The Conventional Sliding Mode Control (C-SMC) strategy has a significant drawback, which is the chattering phenomenon, caused by the discontinuous control signal. The proposed ST-SMC technique based on second-order continuous sliding mode control reduces powers, currents, and torque ripples, while maintaining the advantages of the conventional method (C-SMC) such as the robustness against parametric variations of the DFIG. Simulation results show the effectiveness of the proposed ST-SMC strategy in reducing the chattering effect comparatively to the C-SMC one.
\end{abstract}

Keywords: Wind energy, DFIG, second order sliding mode control, chattering phenomenon, robustness.

\section{INTRODUCTION}

Wind energy is the most promising renewable source of electrical power generation for the future. Many countries promote wind power technology through various national programs and market incentives. Wind energy technology has evolved rapidly over the past three decades with increasing rotor diameters and advanced power electronics to allow operation at the variable speed [1].

Since twenties years, the concept of the variable speed wind turbine (VSWT) equipped with a doubly fed induction generator (DFIG) has received increasing attention due to its noticeable advantages over other wind turbine concepts. In the DFIG concept, the stator is usually connected directly to the three-phase grid; the rotor is also connected to the grid but via a transformer and two backto-back converters. Usually, the rotor-side converter (RSC) controls the active and reactive powers and the grid side converter (GSC), controls the DC-link voltage and ensures operation of the converter at a unity power factor [2]. This arrangement provides the flexibility of operation in sub and super-synchronous speeds in both generating and motoring modes $( \pm 30 \%$ around the synchronous speed). The power inverter needs to handle a fraction $(20-30 \%)$ of the total power to achieve full control of the generator [3].

In the literature, many control methods have been suggested to control DFIG's powers, such as the vector control technique based on traditional Proportional Integral (PI) controllers, due to their simple implementation [4]. However, the classical PI controller may not give satisfactory performance against variations of DFIG parameters [4],[5].

In recent years, many robust control techniques have been proposed in the literature to improve the operation performances of the DFIG. The sliding mode control (SMC) strategy has been widely used for robust control of nonlinear systems. Sliding mode control, based on the theory of variable structure systems (VSS), has attracted a lot of research on control systems for the last two decades. It achieves robust control by adding a discontinuous control signal across the sliding surface, satisfying the sliding condition. However, this type of control has an essential disadvantage, which is the chattering problem caused by the discontinuous control action [6].

In this paper, the Super-Twisting Sliding Mode Control (ST-SMC) has been introduced to overcome the chattering problem while keeping the convergence properties in finite time and robustness of Conventional Sliding Mode Control (C-SMC). In ST-SMC approach, the discontinuous term no longer appears directly in the expression of the synthesized control but in one of its higher derivatives, which has the merit of reducing chattering [7].

Finally, simulation results show that the proposed STSMC strategy effectively reduces the powers and currents ripples as well as minimal mechanical stress on the rotor of the DFIG, compared to the C-SMC strategy.

\section{MODELING OF THE DFIG}

The equivalent circuit of the DFIG in the synchronous reference frame rotating at the angular synchronous speed $\omega_{s}$ is depicted in Fig.1.

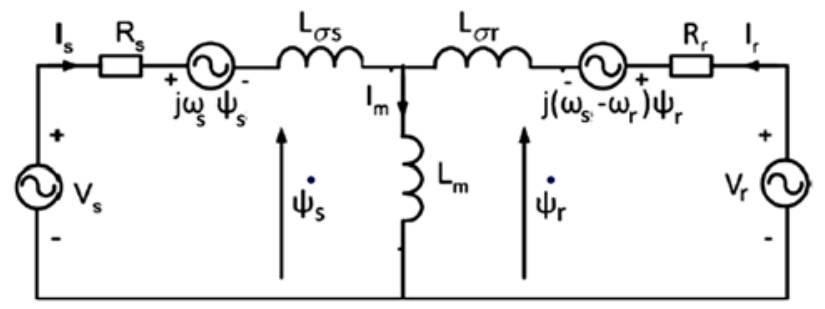

Fig. 1 DFIG equivalent circuit in the synchronous reference frame

The model of the DFIG in the synchronous $d-q$ reference frame is given by the following equations: Stator voltage components:

$$
\left\{\begin{array}{l}
V_{d s}=R_{s} I_{d s}+\frac{d}{d t} \psi_{d s}-\omega_{s} \psi_{q s} \\
V_{q s}=R_{s} I_{q s}+\frac{d}{d t} \psi_{q s}+\omega_{s} \psi_{d s}
\end{array}\right.
$$


Rotor voltage components:

$\left\{\begin{array}{l}V_{d r}=R_{r} I_{d r}+\frac{d}{d t} \psi_{d r}-\left(\omega_{s}-\omega_{r}\right) \psi_{q r} \\ V_{q r}=R_{r} I_{q r}+\frac{d}{d t} \psi_{q r}+\left(\omega_{s}-\omega_{r}\right) \psi_{d r}\end{array}\right.$

Stator flux components:

$\left\{\begin{array}{l}\psi_{d s}=L_{s} I_{d s}+L_{m} I_{d r} \\ \psi_{q s}=L_{s} I_{q s}+L_{m} I_{q r}\end{array}\right.$

Rotor flux components:

$\left\{\begin{array}{l}\psi_{d r}=L_{r} I_{d r}+L_{m} I_{d s} \\ \psi_{q r}=L_{r} I_{q r}+L_{m} I_{q s}\end{array}\right.$

(4) Replacing the stator currents by their expressions given in

DFIG electromagnetic torque:

$$
T_{e m}=\frac{3}{2} p \frac{L_{m}}{L_{s}}\left(\psi_{q s} I_{d r}-\psi_{d s} I_{q r}\right)
$$

Mechanical equation:

$T_{t}=T_{e m}+J \frac{d \Omega_{r}}{d t}+f_{r} \Omega_{r}$

The expressions of the generator's active and reactive power on the stator side are:

$$
\left\{\begin{array}{l}
P_{s}=\frac{3}{2}\left(V_{d s} I_{d s}+V_{q s} I_{q s}\right) \\
Q_{s}=\frac{3}{2}\left(V_{q s} I_{d s}-V_{d s} I_{q s}\right)
\end{array}\right.
$$

The rotor-side converter is controlled in a synchronously rotating $d-q$ axis frame, with the $d$-axis oriented along the stator flux vector position. The effect of the stator resistance can be neglected and the stator flux can be held constant as the stator is connected to the grid. Consequently [8]:

$$
\psi_{d s}=\psi_{s} \text { and } \psi_{q s}=0
$$

Since the stator is directly connected to the grid and the stator flux can be considered constant, and if the voltage dropped in the stator resistance has been neglected [9], the voltage equations, flux equations, currents equations and stator active and reactive powers equations can be simplified in study state as:

$$
\left\{\begin{array}{l}
V_{d s}=0 \\
V_{q s}=V_{s}=\omega_{s} \cdot \psi_{s}
\end{array}\right.
$$
(11), the equations below are expressed by:

$$
\left\{\begin{array}{l}
\psi_{s}=L_{s} I_{d s}+L_{m} I_{d r} \\
0=L_{s} I_{q s}+L_{m} I_{q r}
\end{array}\right.
$$

$$
\left\{\begin{array}{l}
I_{d s}=\frac{\psi_{s}}{L_{s}}-\frac{L_{m}}{L_{s}} I_{d r} \\
I_{q s}=-\frac{L_{m}}{L_{s}} I_{q r}
\end{array}\right.
$$

$$
\left\{\begin{array}{l}
P_{s}=\frac{3}{2} V_{s} I_{q s} \\
Q_{s}=\frac{3}{2} V_{s} I_{d s}
\end{array}\right.
$$

$$
\left\{\begin{array}{l}
P_{s}=-\frac{3}{2} \frac{L_{m}}{L_{s}} V_{s} I_{q r} \\
Q_{s}=\frac{3}{2} V_{s}\left(\frac{V_{s}}{L_{s} \cdot \omega_{s}}-\frac{L_{m}}{L_{s}} I_{d r}\right)
\end{array}\right.
$$

The electromagnetic torque is as follows:

$$
T_{e m}=-\frac{3}{2} p \frac{L_{m}}{L_{s}} \psi_{s} I_{q r}
$$

\section{CONVENTIONAL SLIDING MODE CONTROL OF DFIG}

In order to control the stator active and reactive powers and for a relative degree equal to 1 , the expression of the surface has the form:

$\left\{\begin{array}{l}S_{1}=P_{s}^{*}-P_{s} \\ S_{2}=Q_{s}^{*}-Q_{s}\end{array}\right.$

Where:

$P_{s}{ }^{*}$ and $Q_{s}{ }^{*}$ are successively the references of the active and reactive powers.

The derivative of the surface is:

$$
\left\{\begin{array}{l}
\dot{S}_{1}=\dot{P}_{s}^{*}-\dot{P}_{s} \\
\dot{S}_{2}=\dot{Q}_{s}^{*}-\dot{Q}_{s}
\end{array}\right.
$$

We replace the derivatives of the active and reactive powers by their expressions in (16), we obtain:

$$
\left\{\begin{array}{l}
\dot{S}_{1}=\dot{P}_{s}^{*}+\frac{3}{2} V_{s} \frac{L_{m}}{L_{s}}\left(f_{2}+\frac{V_{q r}}{\sigma L_{r}}\right) \\
\dot{S}_{2}=\dot{Q}_{s}^{*}+\frac{3}{2} V_{s} \frac{L_{m}}{L_{s}}\left(f_{1}+\frac{V_{d r}}{\sigma L_{r}}\right)
\end{array}\right.
$$


Where:

$$
\left\{\begin{array}{l}
f_{1}(x)=-\frac{R_{r}}{\sigma L_{r}} I_{d r}+g \omega_{s} I_{q r} \\
f_{2}(x)=-g \omega_{s} I_{d r}-\frac{R_{r}}{\sigma L_{r}} I_{q r}-\frac{g L_{m} V_{s}}{\sigma L_{s} L_{r}}
\end{array}\right.
$$

Where: $\sigma=1-\left(L_{m}^{2} / L_{s} L_{r}\right)$ is the leakage factor, and $g$ is the slip of the induction machine.

According to the sliding mode theory, we replace respectively $V_{d r}$ and $V_{q r}$ by $V_{d r}{ }^{n}+V_{d r}{ }^{e q}$ and $V_{q r}{ }^{n}+V_{q r}{ }^{e q}$ in (17), we have:
$\left\{\begin{array}{l}V_{q r}^{e q}=-\frac{2}{3} \frac{\sigma L_{s} L_{r}}{V_{s} L_{m}} P_{s}^{*}-\sigma L_{r} f_{2} \\ V_{d r}^{e q}=-\frac{2}{3} \frac{\sigma L_{s} L_{r}}{V_{s} L_{m}} Q_{s}^{*}-\sigma L_{r} f_{1}\end{array}\right.$

By definition, the discontinuous terms $V_{d r}^{n}$ and $V_{q r}^{n}$ are given by [10]:

$\left\{\begin{array}{l}V_{q r}^{n}=-k_{1} \operatorname{sign}\left(S_{1}\right) \\ V_{d r}^{n}=-k_{2} \operatorname{sign}\left(S_{2}\right)\end{array}\right.$

So that the control system becomes asymptotically stable, the gains $k_{1}$ and $k_{2}$ must be positives [11]. The chosen values of $k_{1}$ and $k_{2}$ are 90000 .

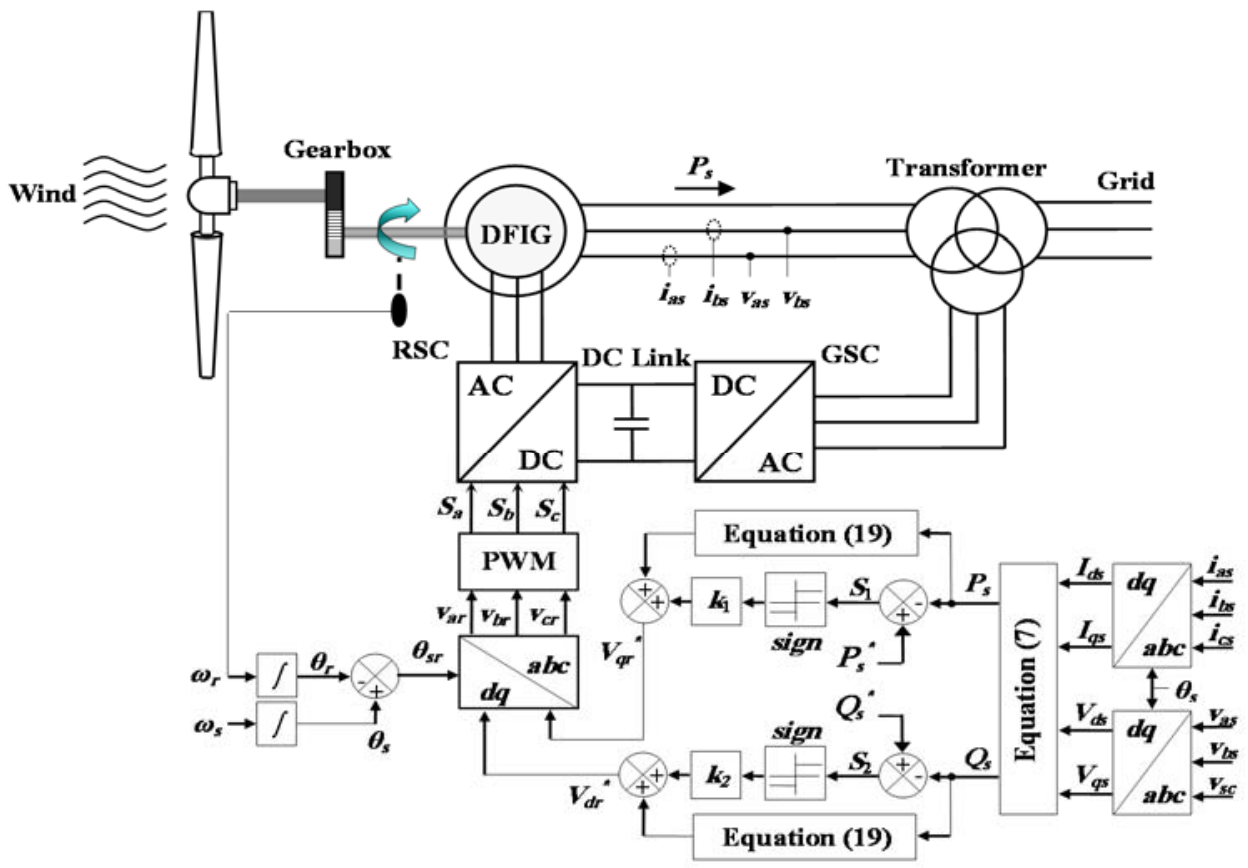

Fig. 2 Block diagram of the conventional sliding mode control of the DFIG

The Fig. 2 shows the block diagram of the conventional sliding mode control of the DFIG.

\section{SUPER-TWISTING SLIDING MODE CONTROL}

\subsection{General Principle of ST-SMC}

Higher-order sliding modes were introduced by Emelyanov [12] and Levantovsky [13]. They represent an extension of the first order sliding modes to a higher degree. This generalization retains the main characteristic in terms of robustness than that of conventional sliding modes. They also reduce their main disadvantage: the chattering effect in the vicinity of the sliding surface. The extension of firstorder sliding modes to higher-order sliding modes is characterized by the choice of discontinuous control acting not on the sliding surface but on its higher derivatives [7], [14].
The purpose of this type of controllers is to generate a second-order sliding regime on a surface $S$ by the cancellation of $S$ itself as well as its derivative in a finite time ( $S=\dot{S}=0$ ). The main feature of this strategy is that the discontinuous part appears on the derivative of the control $\dot{u}$. Finally, when one calculates the control of the system $u=\int \dot{u}$, it becomes continuous thus limiting the chattering problem [14], [15].

The Super-Twisting algorithm is one of the most widely used second-order sliding mode algorithms. This algorithm only applies to systems that have one relative degree [16].

The convergence of this algorithm is governed by rotations around the origin of the phase plane (also called Twisting), as shown in Fig.3. The control law of SuperTwisting is formed of two parts. The first $u_{l}$ is defined by its derivative with respect to time, while the second $u_{2}$ is continuous and according to the sliding variable. For a real sliding mode, the control law will be given by [17]: 


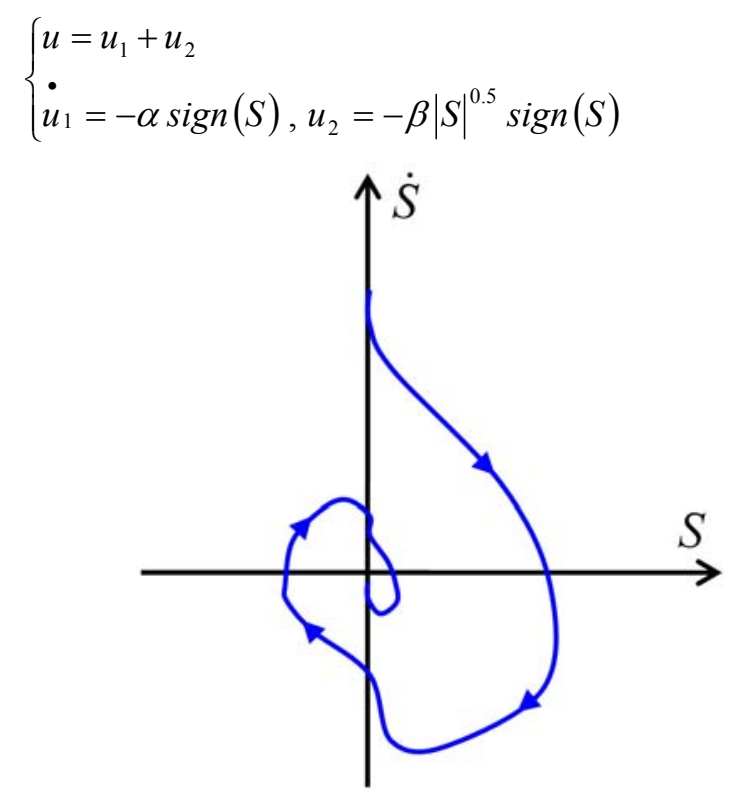

Fig. 3 Convergence in finite time of the Super-Twisting algorithm

Then the proposed control law applied in this paper is given by the following equation [7], [14]:

$u(t)=-l_{1}|S|^{a_{1}} \operatorname{sign}(S) \ldots-l_{n}\left|S^{(n-1)}\right|^{a_{n}} \operatorname{sign}\left(S^{(n-1)}\right)-v$

Where: $v$ is defined by (23) and (24) and the scalars $a_{l}$, $a_{2}, \ldots, a_{n}$ satisfy (25). In addition, $l_{l}, l_{2}, \ldots, l_{n}$ are scalars coefficients defined such that the $n$th order polynomial $p^{n}+l_{n} p^{n-1}+\ldots+l_{2} p+l_{1}$ is Hurwitz.

$v(t)=-L|S|^{0.5} \operatorname{sign}(S)+v_{1}(t)$

$\dot{v}_{1}(t)=-K \operatorname{sign}(S)$

Where $K$ and $L$ are positives constants.

$a_{i-1}=\frac{a_{i} a_{i-1}}{2 a_{i+1}-a_{i}}, i=2, \ldots, n$

Where: $a_{n}+1=1$ and $a_{n}=a$.

\subsection{Application of ST-SMC on DFIG}

The proposed control strategy is based on the supertwisting algorithm defined in the previous section. This strategy has been used in some specific applications, but its exploitation in the control of renewable energy systems, and in particular the wind generators, is recent.

Based on the super-twisting algorithm introduced by Levant in [18], [19] the proposed second order gliding mode control contains two parts:

$V_{q r}^{*}=v_{1}+v_{2}$
Where:

$\left\{\begin{array}{l}\dot{v}_{1}=-k_{1} \operatorname{sign}\left(S_{1}\right) \\ v_{2}=-l_{1}\left|S_{1}\right|^{0.5} \operatorname{sign}\left(S_{1}\right)\end{array}\right.$

And:

$V_{d r}^{*}=w_{1}+w_{2}$

Where:

$\left\{\begin{array}{l}\dot{w}_{1}=-k_{2} \operatorname{sign}\left(S_{2}\right) \\ w_{2}=-l_{2}\left|S_{2}\right|^{0.5} \operatorname{sign}\left(S_{2}\right)\end{array}\right.$

Where stator active power error $S_{I}=P_{s} *_{-} P_{s}$ and stator reactive power error $S_{2}=Q_{S}{ }^{*} Q_{s}$ are the sliding variables, and constant gains $k_{l}$ and $k_{2}$ verify the stability conditions.

\subsection{Stability and gain choice}

Consider the dynamic system with input $u$, state $x$, and output $y$, given as follows:

$\frac{d x}{d t}=a(x, t)+b(x, t) u \quad ; \quad y=c(x, t)$

The main problem of the control is to determine input function $u=f(y, \dot{y})$ whereas it can drive the system trajectories to the initial point $y=\dot{y}=0$ of the phase plane in a limited time [7], [20]. The input $u$ is defined as a new state variable and the switching control is applied to its time derivative $\dot{u}$. The output $\mathrm{y}$ is controlled by an ST-SMC controller with sliding variable $S=y^{*}-y$.

This control strategy does not use the derivative of the sliding variable. As show in (26) and (28), the adequate condition for convergence to the sliding surface and for stability that the gains are large enough [7], [14], [19], [20].

$k_{1}>\frac{A_{m}}{B_{m}} ; k_{2} \geq \frac{4 A_{M}}{B_{m}^{2}} \frac{B_{M}\left(k_{1}+A_{M}\right)}{B_{m}\left(k_{1}-A_{M}\right)}$

Where $A_{M} \geq|A|$ and $B_{M} \geq B \geq B_{m}$ are the superior and inferior bounds of $A$ and $B$, respectively, in the second derivative of $y$.

$\frac{d^{2} y}{d t^{2}}=A(x, t)+B(x, t) \frac{d y}{d t}$

The controller gains $k_{1}$ and $k_{2}$ are designed in order to fulfill the previous conditions and to ensure low content of high frequency components in the control. Indeed, a high gains values can lead to high chattering effects and poor performance [21]. 


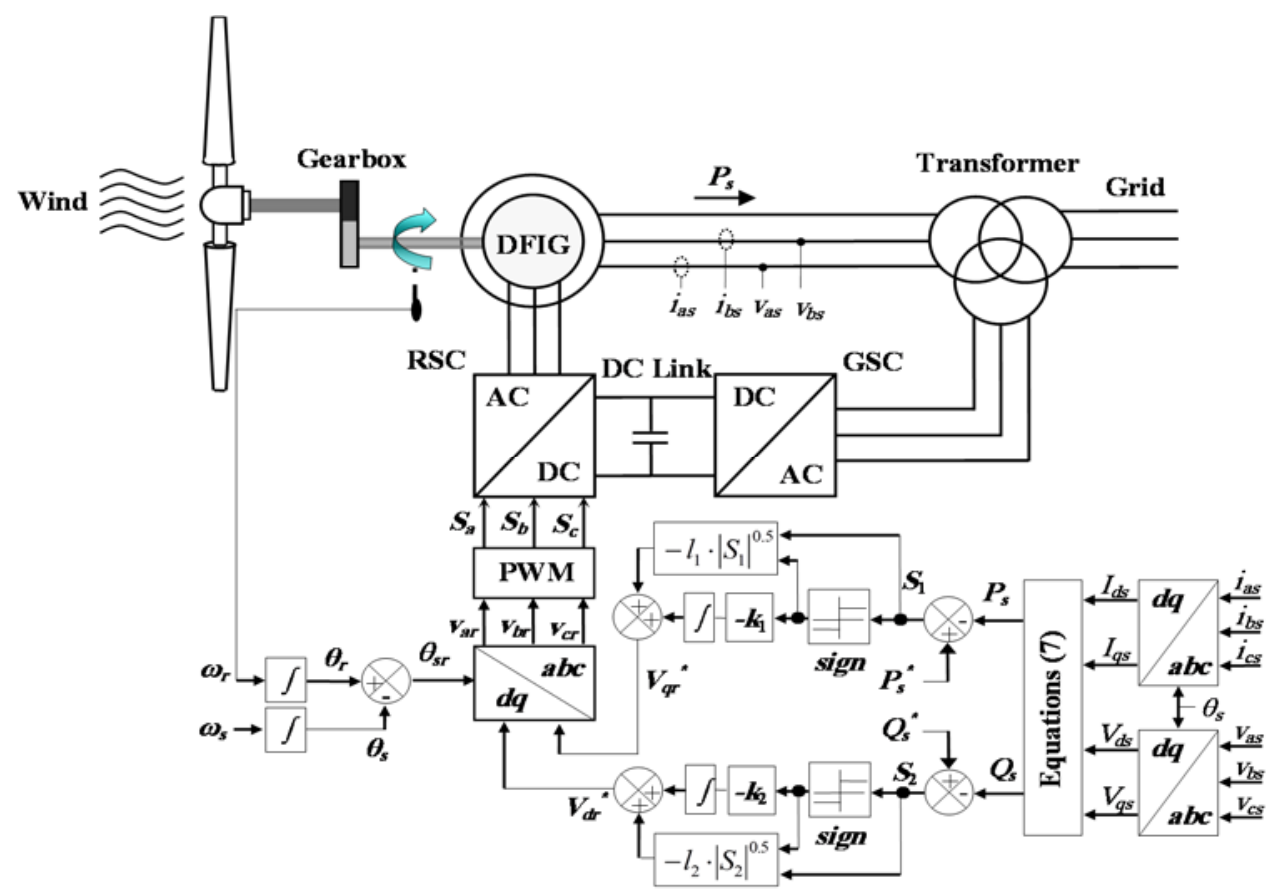

Fig. 4 Block diagram of the super-twisting sliding mode control of the DFIG

The Fig. 4 shows the block diagram of the supertwisting sliding mode control of the DFIG.

\section{SIMULATION RESULTS AND DISCUSSION}

In this section, the C-SMC and the ST-SMC control strategies of 1.5MW DFIG (see Table 1 in appendix) are tested by simulation under MATLAB/SIMULINK software. Both techniques are compared according to three criteria:

1- References tracking test at variable wind speed.

2- Robustness test against the parameters variations of the DFIG at fixed wind speed.

3- Power quality analysis (chattering effect).

\subsection{References tracking test}

In this test, the wind turbine is driven by a variable wind speed with an average value of $8.2 \mathrm{~m} / \mathrm{s}$ (Fig. 5.a). The reference active power is generated by the MPPT (Maximum Power Point Tracking) strategy and the reactive power reference is kept at zero in order to guarantee a unit power factor on the stator side of the DFIG.

The Fig. 5 presents the simulation results of the classical sliding mode control technique (C-SMC) of the DFIG.

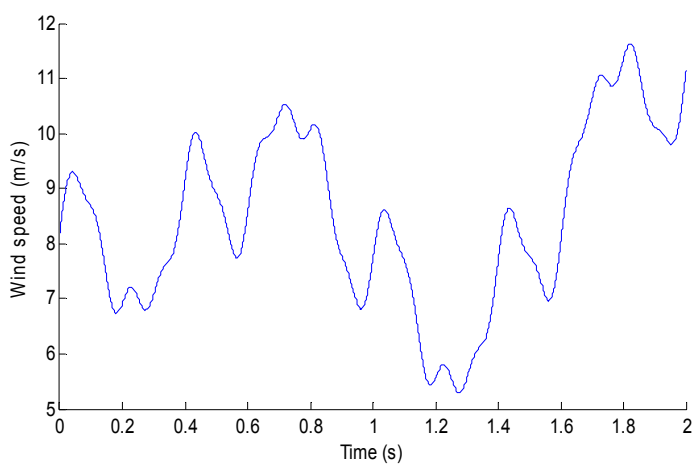

(a) : wind speed

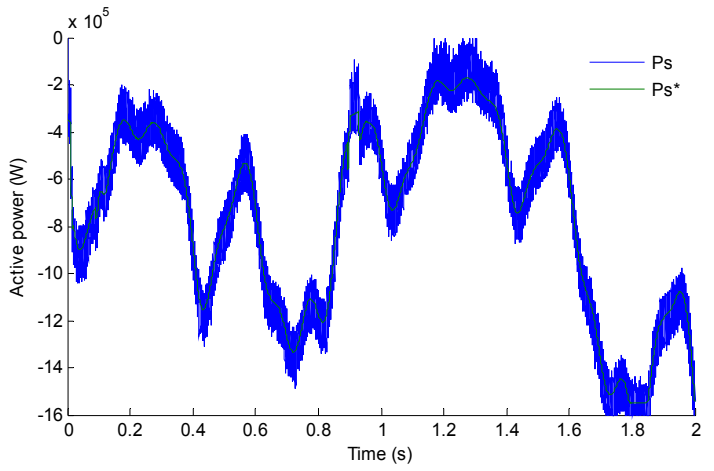

(b) : active power response

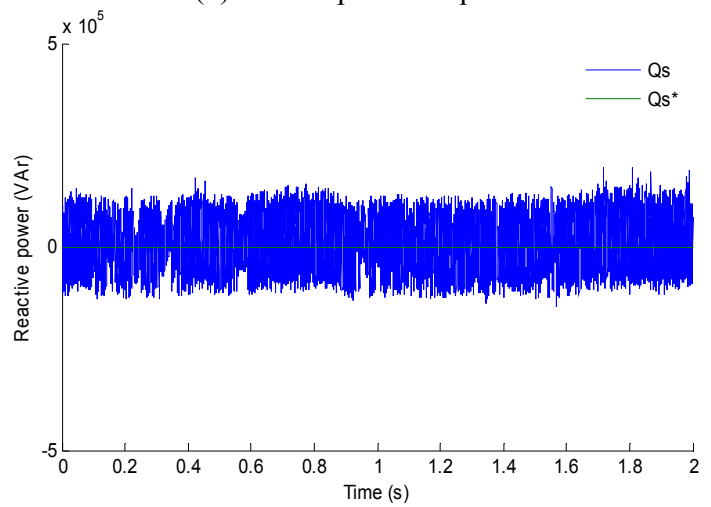

(c) : reactive power response

Fig. 5 Simulation results of C-SMC of DFIG (references tracking test)

The Fig. 5.b shows a very fast response of the active power, where it follows perfectly its reference generated by the MPPT strategy with a negligible error in sub and supersynchronous mode operations of DFIG. The reactive power is maintained at its reference equal to zero (Fig. 5.c), in order to achieve a unit power factor $(\mathrm{FP}=1)$ on the stator side of the DFIG. These simulation results show the high performances of C-SMC strategy of DFIG. 
The Fig. 6 presents the simulation results of the supertwisting sliding mode control (ST-SMC) strategy of the DFIG at the same simulation conditions as the pervious technique (C-SMC).

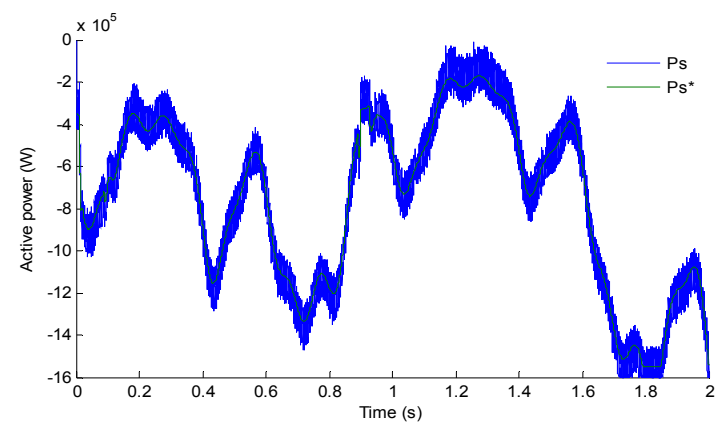

(a) : active power response

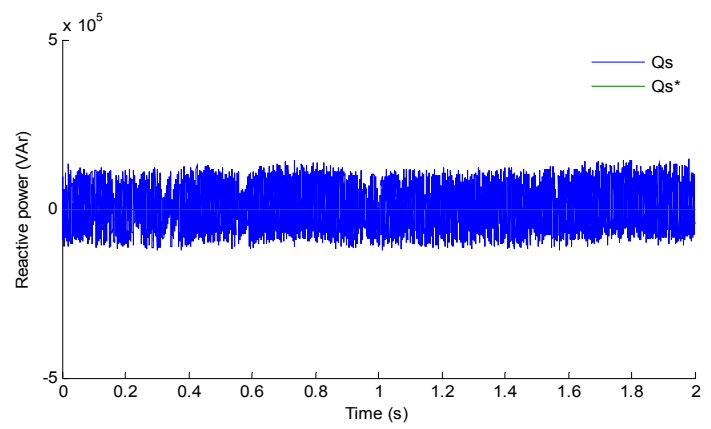

(b) : reactive power response

Fig. 6 Simulation results of ST-SMC of DFIG (references tracking test)

The results in Fig. 6 show clearly the effectiveness of the ST-SMC strategy in the separate control of the active and reactive stator powers of the DFIG. These latter perfectly follow their reference values with a very satisfactory performance.

\subsection{Robustness test}

In order to test the robustness of the tow control strategies C-SMC and ST-SMC of the DFIG, we also studied the influence of parameters variations of the generator on the performances of these last control strategies.

To realize this test, we increase the rotor resistance $\left(R_{r}\right)$ by $100 \%$ of its nominal value (case of warming-up of rotor windings) and decrease the mutual inductance $\left(L_{m}\right)$ by $50 \%$ of its nominal value (case of inductances saturation), at the same time.

Fig. 7 and 8 show the active power, the reactive power, the stator current and the rotor current responses of DFIG for the C-SMC strategy and the proposed ST-SMC scheme respectively, where the wind turbine is driven at fixed wind speed of $12 \mathrm{~m} / \mathrm{s}$.
In this test, the reactive power reference enabled the WECS (Wind Energy Conversion System) to have a negative reactive power (capacitive operating mode) or positive (inductive operating mode). On the other hand, the active power is kept negative, this means that the WECS always generates the active power towards the electrical grid.

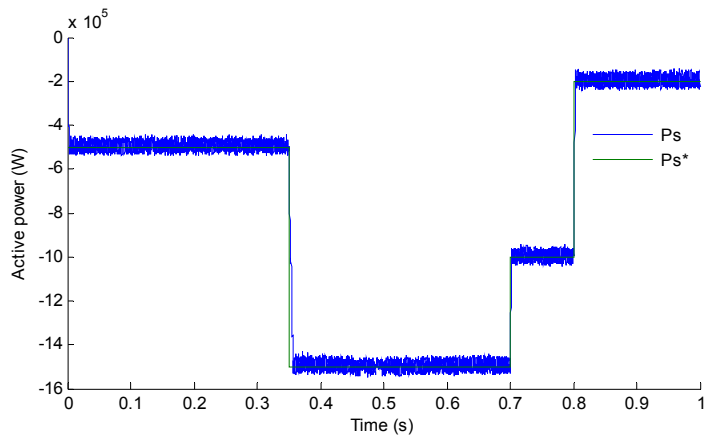

(a) : active power response

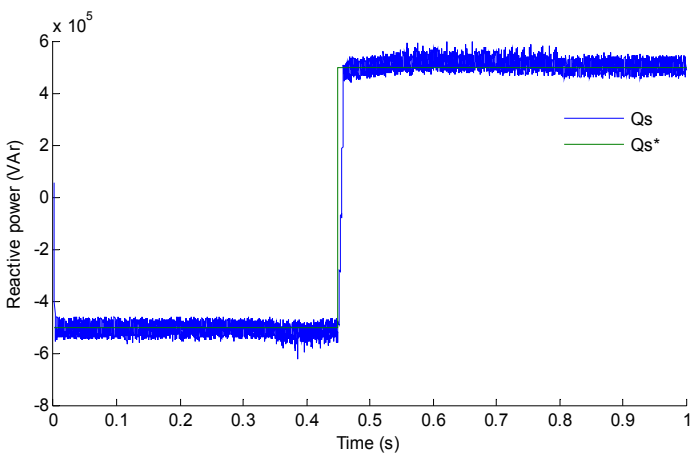

(b) : reactive power response

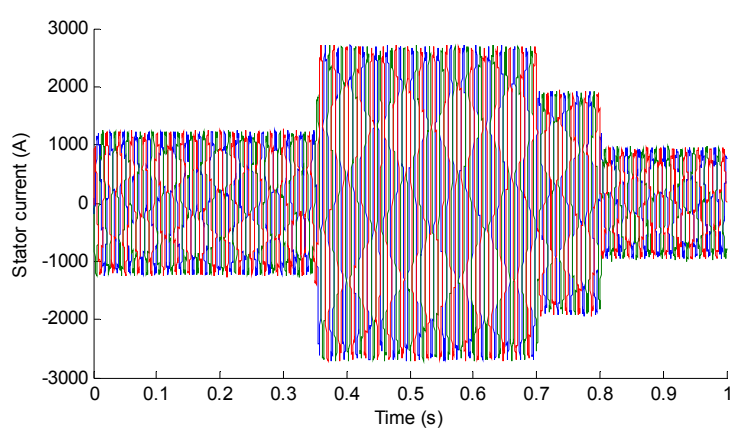

(c) : stator current response

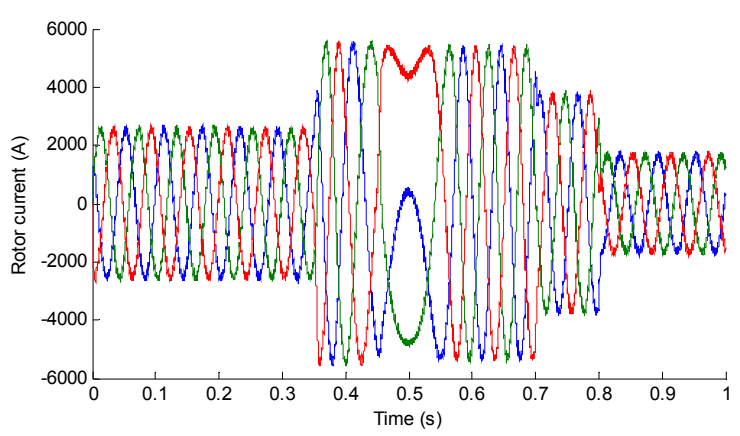

(d) : rotor current response

Fig. 7 Simulation results of the robustness test against parameters variations of DFIG for C-SMC 


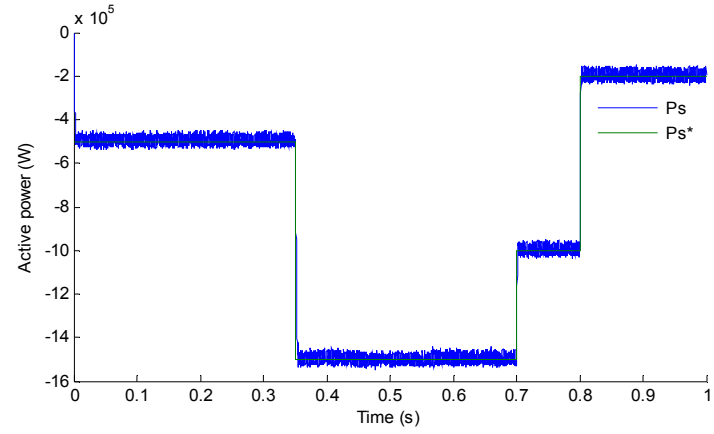

(a) : active power response

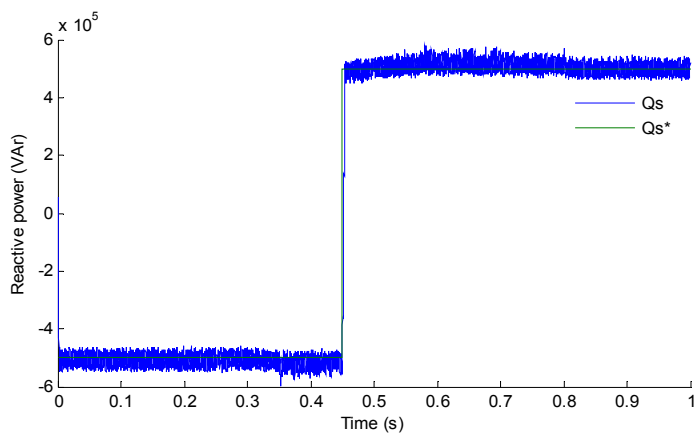

(b) : reactive power response

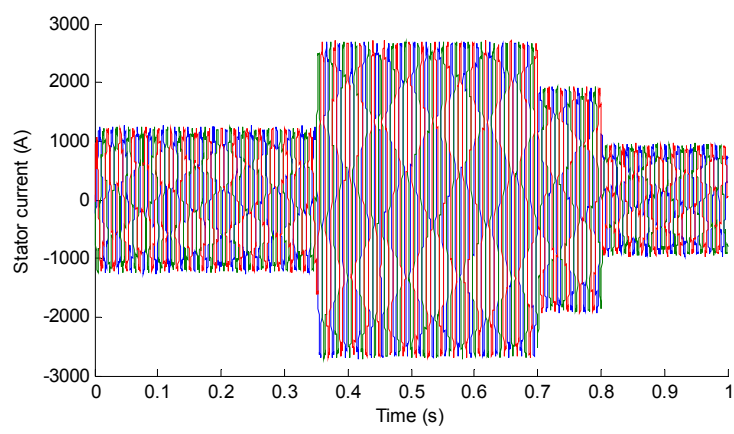

c) : stator current response

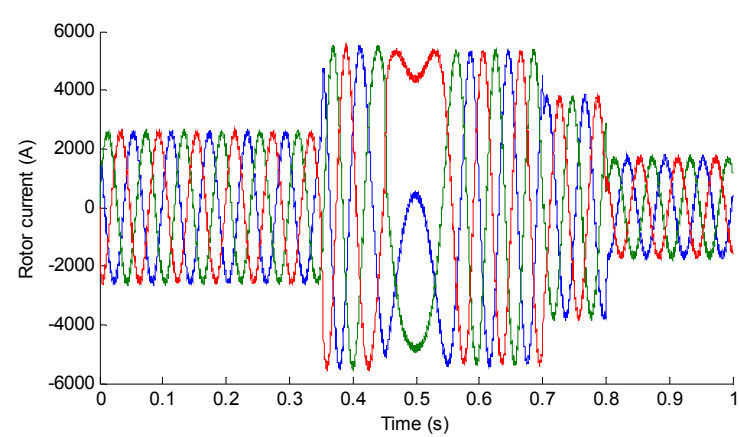

(d) : rotor current response

Fig. 8 Simulation results of the robustness test against parameters variations of DFIG for ST-SMC

Simulation results in Fig. 7 and Fig. 8 show the robustness of both control strategies against parameters variations of the DFIG, contrary to the FOC strategy-based PI (Proportional-Integral) controllers [10], [21].

\subsection{Harmonics analysis test}

This third test is about chattering phenomenon associated to the sliding mode techniques. In this test the Total Harmonic Distortion (THD) of the stator current of the DFIG is measured by using the Fast Fourier Transform
(FFT) method for both C-SMC and ST-SMC control schemes.

Fig. 9 shows the results obtained from the spectral analysis of a phase of the stator current.
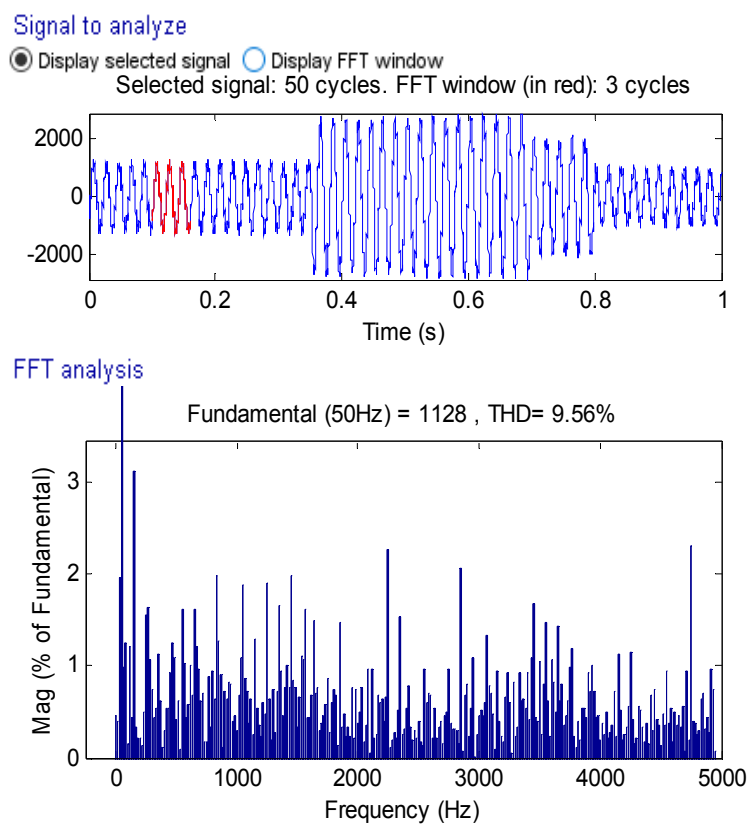

(a) : THD rate of C-SMC
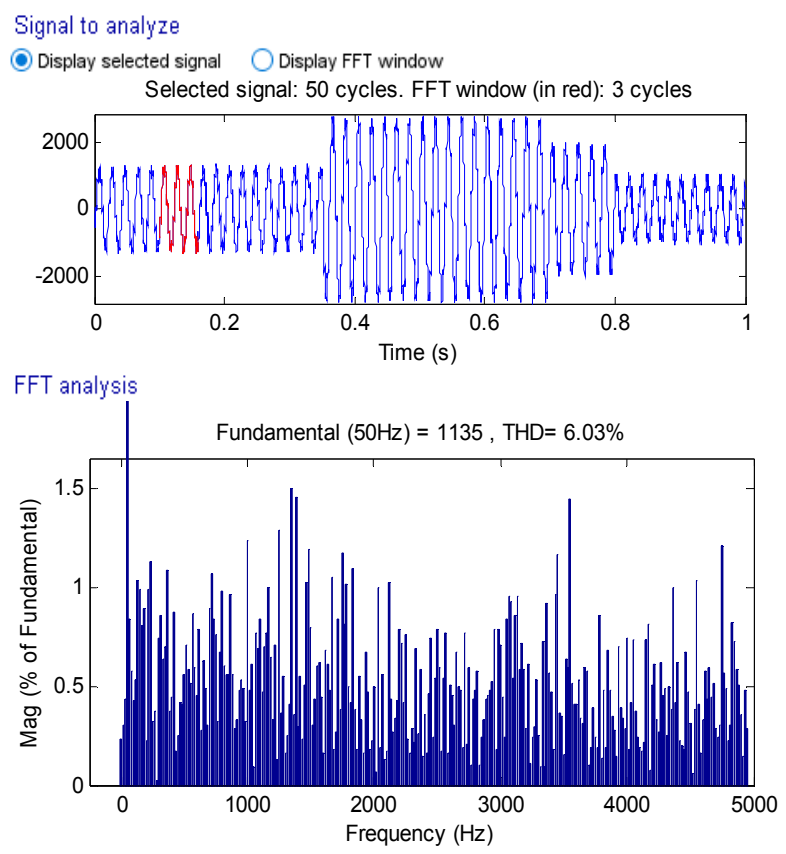

(b) : THD rate of ST-SMC

Fig. 9 Harmonic analysis of the stator current spectrum

The Fig. 9.a shows a total harmonic distortion rate equal to $9.56 \%$, this is due to the chattering phenomenon, which represents a big problem of the conventional sliding mode control (C-SMC), its can cause harmful effects on the generator and could damage the mechanical components of a system because the discontinuous control signal [14], [20], [21], [22]. 
The Fig. 9.b shows that the proposed ST-SMC strategy guarantees a better quality of the stator current waveform injected to the grid, where the total harmonic distortion (THD) rate is only $6.03 \%$.

\section{CONCLUSION}

In this paper there have been presented two robust nonlinear control strategies, C-SMC and ST-SMC, allowing independent control of the active and reactive stator powers of the DFIG, driven by a variable speed wind turbine. The performances obtained by these two control strategies are very satisfactory even in the presence of parameters variations as shown by the trajectory tracking and the fast convergence of the measured variables towards their desired references. However, because of the discontinuous component, C-SMC technique has a higher harmonic distortion level on the output variables, compared to the ST-SMC scheme. Finally, from the simulation results, it can be said that the proposed ST-SMC control strategy of DFIG is a very simple robust control algorithm which has the advantage of being easily for a real time implementation.

\section{APPENDIX}

Table 1 Wind energy conversion system parameters

\begin{tabular}{lll}
\hline \multicolumn{1}{c}{ Parameter } & Rated Value & Unit \\
\hline \hline Rated power, $P_{n}$ & 1.5 & $\mathrm{MW}$ \\
Blade radius, $R$ & 35.25 & $\mathrm{~m}$ \\
Number of blades & 3 & - \\
Gearbox ratio, $G$ & 90 & - \\
Total moment of inertia, $J$ & 1000 & $\mathrm{~kg} \cdot \mathrm{m}^{2}$ \\
Viscous friction coefficient, $f_{r}$ & 0.0024 & $\mathrm{~N} \cdot \mathrm{m} \cdot \mathrm{s}^{-1}$ \\
Nominal wind speed, $v$ & 12 & $\mathrm{~m} / \mathrm{s}$ \\
Stator rated voltage, $V_{s}$ & $398 / 690$ & $\mathrm{~V}$ \\
Rotor rated voltage, $V_{r}$ & $225 / 389$ & $\mathrm{~V}$ \\
Rated current, $I_{n}$ & 1900 & $\mathrm{~A}$ \\
Stator rated frequency, $f$ & 50 & $\mathrm{~Hz}$ \\
Stator inductance, $L_{s}$ & 0.0137 & $\mathrm{H}$ \\
Rotor inductance, $L_{r}$ & 0.0136 & $\mathrm{H}$ \\
Mutual inductance, $L_{m}$ & 0.0135 & $\mathrm{H}$ \\
Stator resistance, $R_{s}$ & 0.012 & $\Omega$ \\
\hline Rotor resistance, $R_{r}$ & 0.021 & $\Omega$ \\
\hline Number of pair of poles, $p$ & 2 & - \\
Slip range, g & -0.3 to 0.3 & - \\
\hline
\end{tabular}

\section{REFERENCES}

[1] BOUDJEMA, Z. - MEROUFEL, A. - DJERIRI, Y. BOUNADJA, E.: Fuzzy sliding mode control of a doubly fed induction generator for wind energy conversion, Carpathian Journal of Electronic and Computer Engineering, Vol. 6, No. 2, pp.7-14, 2013.

[2] YAO, J. - LI, H. - LIAO, Y. - CHEN, Z.: An Improved Control Strategy of Limiting the DC-Link Voltage Fluctuation for a Doubly Fed Induction Wind Generator, IEEE transactions on power electronics, Vol. 23, No. 3, pp.1205-1213, 2008.
[3] MULLER, S. - DEICKE, M. -.DE DONCKER, R. $\mathrm{W}$.: Doubly fed induction generator systems for wind turbines, IEEE Industry Applications Magazine, pp. 26-33, 2002.

[4] DJERIRI, Y. - MEROUFEL, A. - MASSOUM, A. BOUDJEMA, Z.: A comparative study between field oriented control strategy and direct power control strategy for DFIG, Journal of Electrical Engineering, Vol. 14, No. 2, pp. 169-178, 2014.

[5] DJERIRI, Y. - MEROUFEL, A. - ALLAM, M.: Artificial neural network-based robust tracking control for doubly fed induction generator used in wind energy conversion systems, Journal of Advanced Research in Science and Technology, Vol. 2, No. 1, pp. 173-181, 2015.

[6] BOUDJEMA, Z. - MEROUFEL, A - BOUNADJA, E. Y - DJERIRI, Y.: Nonlinear control of a doubly fed induction generator supplied by a matrix converter for wind energy conversion systems, Journal of Electrical Engineering, Vol. 13, No. 4, pp. 60-68, 2013.

[7] BOUYEKNI, A. - TALEB, R. - BOUDJEMA, Z. KAHAL, H.: A second-order continuous sliding mode based on DPC for wind-turbine-driven DFIG, Journal of Electrical Engineering and Computer Science, Vol. 85, No. 2, pp. 29-36, 2018.

[8] HOPFENSPERGER, B. - ATKINSON, D.J. LAKIN, R.: Stator-flux-oriented control of a doublyfed induction machine with and without position encoder, In: IEE Proc.-Electr. Power Applications, Vol. 147, No. 4, pp. 241-250, 2000.

[9] TAPIA, G. - TAPIA, A. - OSTOLAZA, J. X.: Proportional-integral regulator based approach to wind farm reactive power management for secondary voltage control, IEEE Trans. Energy Conversion, Vol. 22, pp. 488-498, 2007.

[10] ALLAM, M. - DEHIBA, B. - ABID, M. MOUILAH, K. - DJERIRI, Y.: A comparative study between field-oriented control and sliding mode control for DFIG integrated in wind energy system, Journal of Electrical Engineering, Vol. 15, No. 3, pp. 01-09, 2015.

[11] SHAH, A. P. - MEHTA, A. J.: Direct power control of grid-connected DFIG using variable gain supertwisting sliding mode controller for wind energy optimization, 43 ${ }^{\text {rd }}$ Annual Conference of the IEEE Industrial Electronics Society, Beijing, China, pp. 2448-2454, October 2017.

[12] EMELYANOV, S.V. - KOROVIN, S. K. LEVANTOVSKIY, L.V.: A drift algorithm in control of uncertain processes, Pob. Control Info. Theory, Vol. 15, No. 6, pp. 425-438, 1986.

[13] EMELYANOV, S. V. - KOROVIN, S. K. LEVANTOVSKY, L. V.: Second order sliding modesin controlling uncertain systems, Soviet Journal of Computer and System Science, Vol. 24, No. 4, pp. 63-68, 1986. 
[14] BOUDJEMA, Z. - TALEB, R. - DJERIRI, Y. YAHDOU, A.: A novel direct torque control using second order continuous sliding mode of a doubly fed induction generator for a wind energy conversion system, Turkish Journal of Electrical Engineering \& Computer Sciences, Vol. 25, pp. 965- 975, 2017.

[15] ANKIT, P. - SHAH, A. - MEHTA, J.: Direct Power Control of DFIG Using Super-Twisting Algorithm Based on Second-Order Sliding Mode Control, In: IEEE $14^{\text {th }}$ international workshop on variable structure systems (VSS), pp. 136-141, 2016.

[16] HAFIANE, M. - SABOR, J. - TALEB, M. GUALOUS, H. - CHAOUI, H.: Adaptive Second Order Sliding Mode Speed Control of Doubly Fed Induction Generator Wind Turbines, IEEE $3^{\text {rd }}$ International Renewable and Sustainable Energy Conference, Marrakech, Morocco, pp. 2380-7393, December 2015.

[17] BELABBAS, B. - ALlAOUI, T. - TADJINE, M. DENAI, M.: Higher performances of the supertwisting sliding mode controller for indirect power control of wind generator based on a doubly fed induction generator, $5^{\text {th }}$ International Conference on Electrical Engineering, Boumerdes, Algeria, October 2017.

[18] LEVANT, A. - ALELISHVILI, L.: Integral highorder sliding modes, IEEE Trans. Automatic Control, Vol. 52, no. 7, pp. 1278-1282, 2007.

[19] RAVAND LAT LEILY, M. - TOHIDI, S. HASHEMZADEH, F. - MOHAMMADPOUR SHOTORBANI, M. : Novel sliding mode controller for power control of a doubly fed induction generator in variable speed wind turbine, IEEE Iranian Conference on Renewable Energy \& Distributed Generation, Tehran, Iran, June 2019.
[20] EL AZZAOUI, M. - MAHMOUDI, H. BOUDARAIA, K. - ED-DAHMANI, C.: FPGA implementation of super twisting sliding mode control of the doubly fed induction generator, IEEE $14^{\text {th }}$ International Multi-Conference on Systems, Signals \& Devices, Marrakech, Morocco, March 2017.

[21] BOUBZIZI, S. - ABID, H. - EL HAJJAJI, A. CHAABANE, M.: Comparative study of three types of controllers for DFIG in wind energy conversion system, Protection and Control of Modern Power Systems, Springer, Vol. 3, No. 21, pp. 1-12, 2018.

[22] KARA, T. - MARY, A. H.: Robust trajectory tracking control of robotic manipulators based on model-free PID-SMC approach, Journal of Engineering Research, Vol. 6, pp. 170-188, 2018.

Received June 2, 2020, accepted June 26, 2020

\section{BIOGRAPHY}

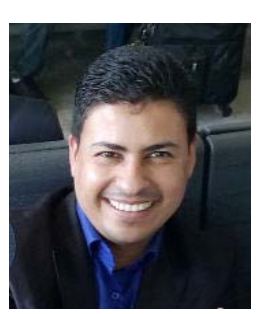

Youcef Djeriri was born in Algeria in 1984. He received the $\mathrm{PhD}$ degree in Electrical Engineering from the Electrical Engineering Faculty of Djillali Liabes University at Sidi BelAbbes, Algeria, in 2015. He is a member of Intelligent Control \& Electrical Power Systems - ICEPS research laboratory. His research interests are in the field of robust, advanced and intelligent control methods of $\mathrm{AC}$ drives associated with power electronic converters for the renewable energy applications. E-mail: youcef.djeriri@univ-sba.dz 